\title{
Neo-Smithian Economics? (After Sraffa)
}

\author{
Mario de Marchi \\ CNR-IRCRES, Consiglio Nazionale Delle Ricerche, Istituto di Ricerca Sulla Crescita Economica Sostenibile, \\ Roma, Italy \\ Email: mario.demarchi@ircres.cnr.it
}

How to cite this paper: de Marchi, M. (2020). Neo-Smithian Economics? (After Sraffa). American Journal of Industrial and Business Management, 10, 1853-1856. https://doi.org/10.4236/ajibm.2020.1012115

Received: October 14, 2020

Accepted: December 20, 2020

Published: December 23, 2020

Copyright $\odot 2020$ by author(s) and Scientific Research Publishing Inc. This work is licensed under the Creative Commons Attribution International License (CC BY 4.0).

http://creativecommons.org/licenses/by/4.0/

\begin{abstract}
In this article, the attempt is made at overcoming some flaws commonly attributed to the economic thought of Adam Smith. It is then argued that such a solution may open up the possibility of fertile links between a Neo-Smithian approach and the John Maynard Keynes' theory of income and employment.
\end{abstract}

\section{Keywords}

Methodology of Economics, Theory of Prices and Income Distribution, Theory of Income and Employment, Consumption Multiplier, Propensity to Savings, Rate of Profit

\section{Introduction: Two Alleged Flaws in the Economic Thought of Adam Smith}

Two ideas put forward by Smith (1994) are usually deemed as incorrect:

I) the proposition that a commodity price could be entirely reduced to incomes paid for its production;

II) the thesis according to which a direct causal link there would exist among an increase of the level in prices and a resulting growth in the profit rate.

The proposition I) is normally rejected by arguing that, as far as the reduction of price goes, a residual made up by means of production multiplied by their values remains and therefore the reduction will never be completed.

The thesis II) is commonly refused by stating that a relationship among prices and profit rate would be a circular one, and therefore no unidirectional, causal link might be derived from it.

Herein we are going to prove that: 1) both such seeming difficulties can be simultaneously overcome by using one analytical tool; 2) this solution opens up the possibility of an immediate integration between John Maynard Keynes' theory of income and employment and a Neo-Smithian approach. 


\section{Sraffa's Standard Commodity: A “Philosopher Stone” for Classical Economics}

Besides being the solution to a question originally posed by David Ricardo of finding an ideal (invariable) measure of values, the Standard Commodity is also the answer for fixing the problems quoted above in I) and II). This may initially come as a surprise to some readers.

Indeed, let us resume a fundamental and clearly stated by Sraffa (1960), although almost always neglected, characteristic of the Standard Commodity: the "recursive" nature of the proportion between subsequent layers of means of production. This characteristic entails that the succession of incomes determined through the reduction of the price of the Standard Commodity will be a regular one, where each term is " $(1+r) /(1+R)$ ", standing as usually $r$ for the rate of profit. In addition, if it always must be " $r<R$ ", namely if $R$ is the maximum rate of profit, the series made up by the sum of this succession is a convergent one. And, since the sum can be calculated in a straightforward way through a sequence of steps finite (in fact very short), in the Standard Commodity instance the reduction of its price can be completed. This solves the problem cited in I) and, as can immediately be ascertained by means of some calculations, the II) as well.

Let us make the hypotheses that: the wage $w$ be paid postfactum; $r$ is the rate of profit; $(1+R)$ is the proportion between two subsequent layers of means of production.

Then, provided that $r<R$, the $V$ value of the Standard Commodity can be worked out as the value of a convergent geometrical series of the sort:

$$
V=w((1+r) /(1+R))^{0}+w((1+r) /(1+R))^{1}+\cdots+w((1+r) /(1+R))^{n}+\cdots
$$

With the value of the series equal to:

$$
V=w(1 /(1-((1+r) /(1+R))))
$$

The result of such peculiar reduction is a new original relationship between the rate of profit and the value of Standard Commodity.

$$
(1+R) /(R-r) w=V
$$

whereby: if, say, $V$ increased from the minimum, viable level $((1+R) / R) W$ (corresponding to no profits) towards the infinity, then $r$ would grow towards a maximum $R$.

Some readers may be puzzled by the difference between Equation (1) and the famous Sraffa's:

$$
r=R(1-w)
$$

In fact, the two are consistent and both correct. Their dissimilarities follow naturally because the second one concerns, as it is well known, the net Standard Product, whereas it is clear that the first one instead regards the gross Standard Product. 
Following a suggestion by Sraffa, we can give the $V$ unit of value a more tangible content by dividing both terms of (1) by $w$ so that in Equation (2) in the second term we obtain the work which $V$ can pay for, namely, in the words of Smith, the work $V$ commands.

$$
(1+R) /(R-r)=V / w
$$

Having reached this preliminary theoretical result, one may be tempted to compare the Neo-Smithian perspective with the Keynesian one, provided some assumptions are made.

\section{Exploring a Possible Symmetry}

A straightforward path to compare the Keynesian and the Neo-Smithian approaches is to bring about a symmetry between the most significant and relevant aspects of both theoretical sets. This way, one could write down a System of formulae in which one included a Keynesian contribution, another represented the Neo-Smithian perspective and finally, a third one set up a clear relationship between the two analytical points of view. Given Equation (1), let us suppose for the sake of simplicity, that: a homogenous commodity is only produced in the Economic system, so that the national income " $P$ " consists only in a quantity of Standard Product $V$; and define as usually the investment as " $P$ " and the propensity to saving as " $s$ ". We can write down the System of equations " $(\sigma \rho . i)$ ":

$$
\begin{array}{ll}
(\sigma \rho .1) & ((1+R) /(R-r))=V / w \\
(\sigma \rho .2) & I / s=Y \\
(\sigma \rho .3) & Y=V
\end{array}
$$

In it, the first formula expresses the value $V$ of the Standard Product; the second formula includes what many scholars consider the most original and illuminating of the contributions by Keynes (1997) to Economic Theory: the concept of multiplier and its role in the determination of national income $Y$; finally, by stating the " $(\sigma \rho .3)$ " equivalence we are implying that:

$$
I / w=s((1+R) /(R-r))
$$

Equation (4) brings about a basic, neat and perhaps empirical testable analytical consequence: such formula expresses the hypothesis that an inverse relationship there exists between the rate of profit and the propensity to saving. Indeed, once determined as in the Keynes' analysis the values of wages and Investments, and taken $R$ as given along with the technology as in Sraffa's scheme, in order to keep the balance between the two sides of the equation: as $r$ grew towards $R, s$ would have to fall from its virtual maximum, one, towards zero, and vice-versa.

\section{Acknowledgements}

This article is dedicated to Dr. Annamaria Scarda-Tedeschi. 


\section{Conflicts of Interest}

The author declares no conflicts of interest regarding the publication of this paper.

\section{References}

Keynes, J. M. (1997). The General Theory of Employment, Interest and Money. Buffalo, NY: Prometheus Books.

Smith, A. (1994). The Wealth of Nations. New York, NY: The Modern Library.

Sraffa, P. (1960). Production of Commodities by Means of Commodities. Cambridge: Cambridge University Press. 